\title{
De doorbraak van de strip als populair medium in de Vlaamse pers van de jaren dertig
}

Hoewel het beeldverhaal al meer dan een eeuw een vast onderdeel van de Nederlandstalige populaire cultuur uitmaakt, blijft het academisch onderzoek hieromtrent nog uitermate beperkt en is er aan geen enkele Nederlandstalige universiteit een vak dat zich specifiek op het stripmedium richt. Ook het onderzoek naar de historische ontwikkeling van het stripmedium staat nog in haar kinderschoenen. Over het vroege beeldverhaal in Vlaanderen en vooral haar doorbraak in de jaren dertig van de vorige eeuw is nog maar heel weinig gepubliceerd. ${ }^{I}$ Uit de internationale literatuur blijkt dat de jaren dertig een cruciale periode vormden in de ontwikkeling van het medium in talrijke landen, zoals de Verenigde Staten, Frankrijk, GrootBrittannië of Italië. ${ }^{2}$ De veranderingen betroffen uiteenlopende maar toch gerelateerde aspecten, zoals de manier waarop beeldverhalen werden gepubliceerd en de evolutie van dominante stilistische en narratieve conventies. Dergelijke ontwikkelingen verliepen niet in elk land op dezelfde manier. Zo was er begin twintigste eeuw een aanzienlijk verschil tussen de Amerikaanse en de Europese strip. Terwijl strips zich in Europa vooral op kinderen richtten, mikten de Amerikaanse strips ook op het volwassen publiek. De efficiënte, grootschalige aanpak van de Amerikaanse syndicates, die talrijke stripauteurs vertegenwoordigden, liet zich ook al snel buiten de Verenigde Staten voelen: zowel in Latijns-Amerikaanse landen als in Japan werden de populairste Amerikaanse strips vertaald, maar nog vaker geïmiteerd. ${ }^{3}$ In Europa was er echter een culturele weerstand tegen de Amerikaanse strips: als men al Ame-

* Pascal Lefêvre doceert over visuele cultuur aan de Hogeschool Sint-Lukas Brussel en aan de MADFaculty. Hij is geaffilieerd onderzoeker aan de K.U. Leuven (Centrum voor Mediacultuur en Communicatietechnologie). Zijn onderzoek over de voorgeschiedenis van het beeldverhaal in België kreeg ondersteuning (2007-2009) van de Onderzoeksraad van Sint-Lukas Brussel. Voor een overzicht van publicaties en papers, zie <sites.google.com/site/lefevrepascal/>. E-mail: lefevre.pascal@gmail.com. Kim Aerts studeerde in 2009-2010 af als Master in de Communicatiewetenschappen aan de K.U. Leuven. Hij verrichtte onderzoek naar het beeldverhaal in de jaren dertig, onder begeleiding van promotor Pascal Lefèvre.

Tim Caenepeel studeerde in 2009-2010 af als Master in de Communicatiewetenschappen aan de K.U. Leuven. Hij verrichtte onderzoek naar het beeldverhaal in de jaren dertig, onder begeleiding van promotor Pascal Lefêvre.

Dieter Minet studeerde in 2009-20I0 af als Master in de Communicatiewetenschappen aan de K.U. Leuven. Hij verrichtte onderzoek naar het beeldverhaal in de jaren dertig, onder begeleiding van promotor Pascal Lefevre. 
rikaanse strips publiceerde, dan aarzelde men zelden om ze ingrijpend aan te passen: zo werden tussen I900 en I930 de tekstballonnen meestal uit de tekeningen gewist en vervangen door tekst onder het beeld. ${ }^{4}$ De tekstballon, die tegenwoordig een prototypisch kenmerk van het stripmedium is, vond in Europa voor de jaren dertig maar met moeite ingang. In de periode I900-I930 nam de hoeveelheid tekst die onderaan de tekeningen werd afgedrukt nog toe in vergelijking met de negentiende eeuw. Ook qua visuele narratie oogden de meeste Europese beeldverhalen aan het begin van de twintigste eeuw statischer dan de gemiddelde Amerikaanse krantenstrip. Kortom, het Europese beeldverhaal was over het algemeen minder attractief voor een breed lezerspubliek dan het Amerikaanse beeldverhaal, maar het zou tot de jaren dertig van de twintigste eeuw duren voordat de Amerikaanse aanpak echt doorbrak in Europa. Enerzijds werden er toen met succes nieuwe stripbladen gelanceerd (die ofwel Amerikaanse strips met ballonnen ofwel Europese imitaties daarvan publiceerden) en anderzijds zou de strip voortaan ook een vast onderdeel worden van de algemene pers.

Dit artikel vormt de neerslag van een onderzoek, waarin werd nagegaan in welke mate deze veranderingen ook in Vlaanderen zichtbaar waren. Hiermee werd voor het eerst diepgaand en systematisch onderzoek verricht naar het beeldverhaal in Vlaanderen in de jaren dertig. 5

\section{Bronnen en methode}

Zeventig jaar na dato waren er geen gegevens beschikbaar over de receptie van strips in de jaren dertig. De productionele context was evenmin goed gedocumenteerd. Daarom zal deze studie zich voornamelijk focussen op hetgeen nu nog - deels - toegankelijk is, namelijk de beeldverhalen zelf. Om een onderscheid te kunnen maken met cartoons (die uit een of twee plaatjes kunnen bestaan), definieren we een 'strip' of 'beeldverhaal' hier als een sequens van minimaal drie getekende of geschilderde plaatjes. ${ }^{6}$ We beperken ons bovendien tot de drie belangrijkste publicatietypes voor beeldverhalen van die tijd: de kranten, de geillustreerde tijdschriften voor volwassenen en de geillustreerde kinder- en jeugdbladen. ${ }^{7}$ Een publicatietype kan immers een sterke invloed uitoefenen op het soort strips dat het opneemt. ${ }^{8}$

Bij twaalf Vlaamse krantentitels uit de jaren dertig werden 83 verschillende stripreeksen gevonden (vaak van honderd afleveringen). 9 Het aantal geillustreerde Vlaamse periodieke bladen voor volwassenen was in die periode (2I titels) talrijker dan het aantal krantentitels, maar omvatte in totaal minder nummers, omdat periodieken per definitie minder frequent verschenen dan een dagblad. ${ }^{\text {Io }}$ Een derde, daarbij aansluitend publicatietype, waren de geillustreerde jeugdbladen, waarvan we 26 titels (en in totaal zo'n I500 nummers) konden inventariseren. In veertien van die 26 onderzochte titels werden er stripverhalen gevonden. ${ }^{\text {II }}$ Wat de kranten en kinderbladen betreft, werden alle beschikbare exemplaren in het onderzoek op- 
genomen. Bij de geïllustreerde tijdschriften voor volwassenen werd echter gewerkt met een willekeurige steekproef (één nummer per kwartaal per titel).

Het cijfermateriaal dat dit opleverde, en waarnaar in dit artikel regelmatig zal worden verwezen, pretendeert niet volledig representatief te zijn, maar volstaat ruimschoots om enkele belangrijke tendensen te identificeren. Het betreft hier uiteraard een verkennend onderzoek, dat toch op een vrij systematische manier de nog toegankelijke bronnen van dat decennium op een objectieve manier poogt in beeld te brengen. In tegenstelling tot de overgrote meerderheid van stripgeschiedenissen die zich meestal focussen op de bekende stripreeksen, willen wij vooral de toenmalige productie in haar breedte en verscheidenheid tot haar recht laten komen. Met dit doel zullen aspecten zoals productionele context, oorsprong (binnenlands of ingevoerd), type (korte gags of vervolgverhalen), aantal en levensduur, uitzicht en de verschijningsvormen van tekst onderzocht worden. Hiermee waren uiteraard niet alle mogelijke aspecten opgenomen, maar de geselecteerde aspecten laten toch toe om ze vrij eenvoudig te kwantificeren, het stripaanbod van de jaren dertig objectief te beschrijven en een aantal essentiële kenmerken te bepalen. Deze aspecten hebben doorgaans ook een striphistorisch belang (zie hiervoor) zoals het gebruik van de tekstballon of de internationale verspreiding van strips. Alle onderzochte publicaties werden, ongeacht het publicatietype, op een gelijksoortige manier gecodeerd, aan de hand van 48 variabelen. Om de betrouwbaarheid van deze gegevens te garanderen, werd voor elk van de drie corpussen een inter/intra-coder reliability test gedaan. ${ }^{\mathrm{I} 2}$

\section{Productionele context}

In eerste instantie gingen we na of er bepaalde patronen te vinden waren op het vlak van de uitgave (plaats, ideologisch profiel, doelpubliek). We lieten daarbij in het midden in welke mate deze aspecten typisch voor het beeldverhaal waren of afweken van de ruimere context van de Vlaamse uitgeverijsector. Als we kijken naar de plaats van uitgave, dan valt het op dat slechts weinig Vlaamse kinderbladen en geïllustreerde bladen in Brussel werden uitgegeven (respectievelijk ı9\% en 8\%), maar veeleer in Antwerpen en in mindere mate in Gent. Belangrijker: op ideologisch vlak waren er ook grote verschillen (zie tabel I). Zo zien we dat een ruime meerderheid van de kinderbladen duidelijk een katholieke stempel had, bij de andere publicatietypes was dat minder het geval: zo hadden de dagbladen een meer verscheiden profiel. (Het liberale Het Laatste Nieuws publiceerde bijvoorbeeld tamelijk veel beeldverhalen.) Het katholieke overwicht op de kinderbladen kan worden uitgelegd als een bewuste poging om ook op jonge leeftijd de kinderen bij de kerk te betrekken. ${ }^{\mathrm{I3}}$ Er werd geen verband vastgesteld tussen het ideologische profiel van enerzijds een bepaalde publicatie en anderzijds van het daarin gepubliceerde beeldverhaal. In tegenstelling tot wat de marxistisch georiënteerde ideologische studies, voornamelijk van de jaren zeventig en tachtig van de twintigste eeuw, pretenderen, 
TABEL 1: $\quad$ Procentuele verhouding tussen de ideologische profielen van publicatietypes

\begin{tabular}{llll}
\hline & Algemene tijdschriften & Kinderbladen & Dagbladen \\
\hline Onbekend of neutraal & $72 \%$ & $38 \%$ & $29 \%$ \\
Katholiek & $\mathrm{I} \% \%$ & $60 \%$ & $15 \%$ \\
Socialistisch & $\mathrm{I0 \%}$ & $\mathrm{I}, 5 \%$ & $7 \%$ \\
Communistisch & $\circ \%$ & $0,5 \%$ & $\circ \%$ \\
Liberaal & $\circ \%$ & $\circ \%$ & $42 \%$ \\
Vlaams-nationalistisch & $\circ \%$ & $\circ \%$ & $7 \%$ \\
\hline
\end{tabular}

was het ideologische profiel van een strip doorgaans complex en weinig eenduidig

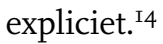

Bij de kinderbladen waren alle strips per definitie voor kinderen bestemd, bij de kranten werden $63 \%$ van de beeldverhalen duidelijk in een kinderrubriek ondergebracht, maar inhoudelijk gezien richtten bijna alle beeldverhalen in de dagbladpers zich tot kinderen (ongeveer 90\%). Bij de algemene geillustreerde tijdschriften werd daarentegen meestal niet met een vaste rubriek gewerkt en werd slechts $5 \%$ van de beeldverhalen expliciet in een kinderrubriek ondergebracht. Dit impliceert vanzelfsprekend niet dat alle andere beeldverhalen in die tijdschriften uitsluitend voor volwassenen bedoeld waren.

\section{Oorsprong van materiaal}

Vanaf de start van het beeldverhaal in de negentiende eeuw was er al een intense internationale uitwisseling. De richting en intensiteit van deze uitwisseling evolueerde echter in de tijd. Ons onderzoek bevestigt niet alleen dat ook in de Vlaamse pers van de jaren dertig een aanzienlijk deel van het gepubliceerde materiaal van buitenlandse oorsprong was, maar brengt deze invloed ook in kaart per publicatietype. De resultaten van de oorsprong van de beeldverhalen dienen echter onder enig voorbehoud gegeven te worden (zie tabel 2 en grafiek I), want ze slaan slechts op ongeveer de helft van het corpus. Vaak waren er immers geen aanduidingen te vinden in verband met hun oorsprong (auteursnaam of naam van oorspronkelijke uitgever). Bij de kranten kon $69 \%$ van de strips geïdentificeerd worden, bij de geillustreerde bladen $52 \%$ en bij de kinderbladen $40 \%$. Toch mogen we aannemen dat enkele grote tendensen allicht representatief zijn voor de toenmalige toestand. Zo is het opmerkelijk dat er grote verschillen tussen de drie publicatietypes zijn. Bij de dagbladen konden geen strips van Belgische oorsprong geïdentificeerd worden, de grootste groep kwam blijkbaar uit Nederland (6r\%) en in mindere mate uit de Verenigde Staten (36\%). Bij de geïllustreerde bladen waren de meeste strips dan weer 
TABEL 2: $\quad$ Procentuele verhouding tussen de landen van oorsprong per publicatietype

\begin{tabular}{llll}
\hline & Algemene tijdschriften & Kinderbladen & Dagbladen \\
\hline Belgisch & $\mathrm{I} 8 \%$ & $54 \%$ & $\circ \%$ \\
Nederlands & $2 \mathrm{I} \%$ & $3 \%$ & $6 \mathrm{I} \%$ \\
Frans & $34 \%$ & $\mathrm{I} \% \%$ & $\circ \%$ \\
Scandinavisch & $31 \%$ & $3 \%$ & $3 \%$ \\
Amerikaans & $\mathrm{I} \%$ & $26 \%$ & $36 \%$ \\
Duits & $3 \%$ & $\circ \%$ & $\circ \%$ \\
Brits & $9 \%$ & $\circ \%$ & $\circ \%$ \\
Italiaans & $\mathrm{I} \%$ & $\circ \%$ & $\circ \%$ \\
\hline
\end{tabular}

van Scandinavische (één op drie) of Nederlandse (één op vijf) oorsprong, in mindere mate van België zelf (I8\%) en van de Verenigde Staten (13\%). Bij de kinderbladen was de grootste groep daarentegen wel van Belgische makelij (64\%) en de rest kwam uit Frankrijk (Iо\%), Nederland (3\%) en Scandinavië (3\%). Vanzelfsprekend werd de originele titel van buitenlandse strips doorgaans vertaald.

\begin{tabular}{ll}
\hline Originele titel & Titel in Vlaamse publicatie \\
\hline Perry and the Rinkydinks & De Avonturen van Ukkie, Wappie en zijn vriendjes \\
Les inventions du Professeur Pouic & De uitvindingen van professor Kanniks \\
Mickey Mouse & Mikkie en Bleskop \\
Popeye & Jan Spinazie \\
Henry & Rikske \\
\hline
\end{tabular}

In de geïllustreerde tijdschriften werden vooral werken van de Scandinaviërs MIK en Oscar Jacobsson, de Nederlander Marten Toonder en de Amerikanen Walt Disney en Martin Branner gepubliceerd. In de kranten was de Nederlander Henricus Kannegieter onmiskenbaar de koploper, met reeksen als De avontuurlijke lotgevallen van Jimmy, Twee jongens in 't jaar 2500 en De snakerijen van Tijl Uilenspiegel. Na Kannegieter kwamen de strips uit de Disney-studio het meest voor: Mickey Mouse, Donald Kwak en Sneeuwwitje en de zeven dwergen. De populairste langeverhaalstrips waren eveneens afkomstig uit het buitenland: Fik en Fok van Marten Toonder en De Avonturen van Ukkie Wappie en zijn vriendjes van Martin Branner. Ook Scandinavische woordloze gagstrips als Adamson en Ferd'nand kwamen verschillende keren voor. In de kinderbladen werd behalve van Walt Disney vooral werk gepubliceerd 


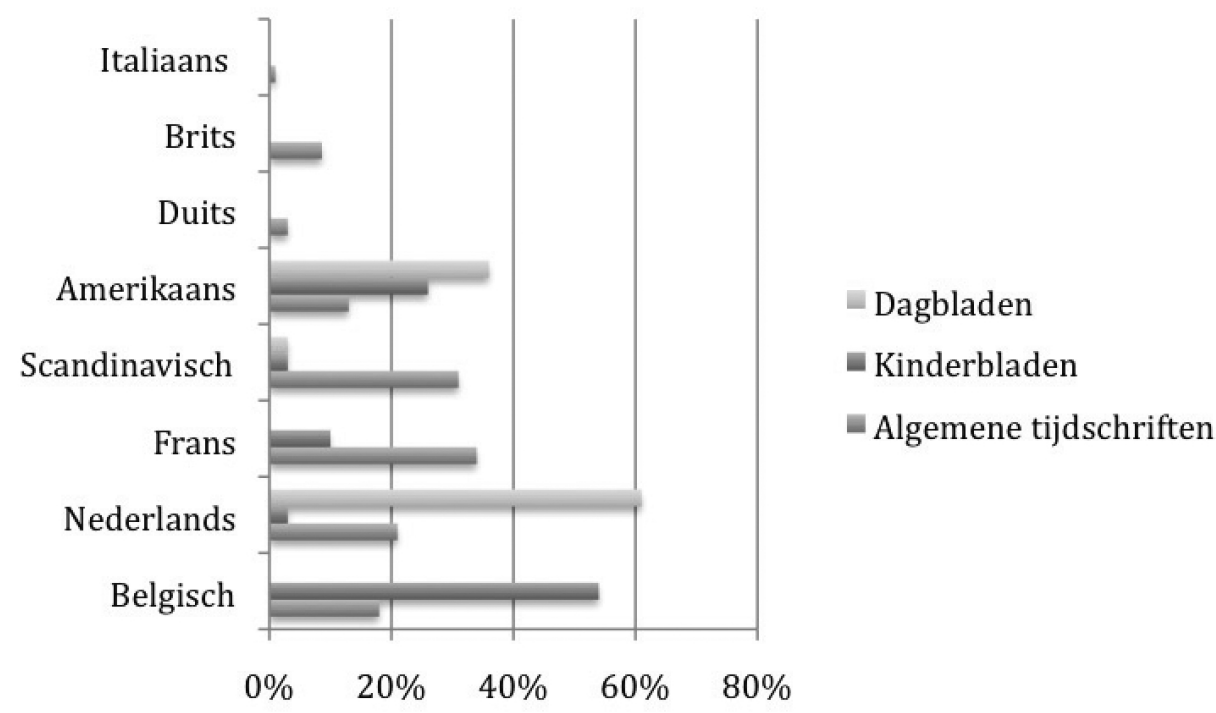

GRAFIEK 1: Verhouding in percentages tussen de landen van oorsprong per publicatietype

van Vlamingen als Pink (Eugeen Hermans), Jan Waterschoot en Frans Van Immerseel. Van de eerste twee werden ook beeldverhalen in de dagbladen aangetroffen.

Uit eerder onderzoek bleek dat al vóór de Eerste Wereldoorlog het grootste deel van de gepubliceerde beeldverhalen in de Belgische geillustreerde tijdschriften voor volwassenen en in de kinderbladen van buitenlandse oorsprong was. ${ }^{15}$ In tegenstelling tot die vroege periode nam het belang van Frankrijk, Duitsland, Groot-Brittannië en Spanje wel af ten voordele van Nederland en de Scandinavische regio die vanaf de jaren twintig, dankzij het PIB-syndicate, een ruime verspreiding in Europa kreeg. ${ }^{16}$ Het beeldverhaal in de Vlaamse pers was in de jaren dertig dus veel noordelijker gericht dan in de decennia voordien. Zowel Nederland als Denemarken hadden in de jaren twintig al een uitgebreidere beeldverhaalcultuur dan Vlaanderen. Deze noordelijke invloed zou nog tot de jaren zestig doorwerken (Vlaamse kranten publiceren dan bijvoorbeeld de Marten Toonder-strips), maar nadien aan belang afnemen.

\section{Losse gags of vervolgverhalen}

De beeldverhalen van de jaren dertig laten zich grofweg indelen in twee verschillende types: enerzijds de korte gagstrip en anderzijds het vervolgverhaal (dat zowel humoristisch als dramatisch kan zijn). Naargelang het publicatietype zien we andere voorkeuren: bijna driekwart van de strips in de kranten waren avontuurlijke 

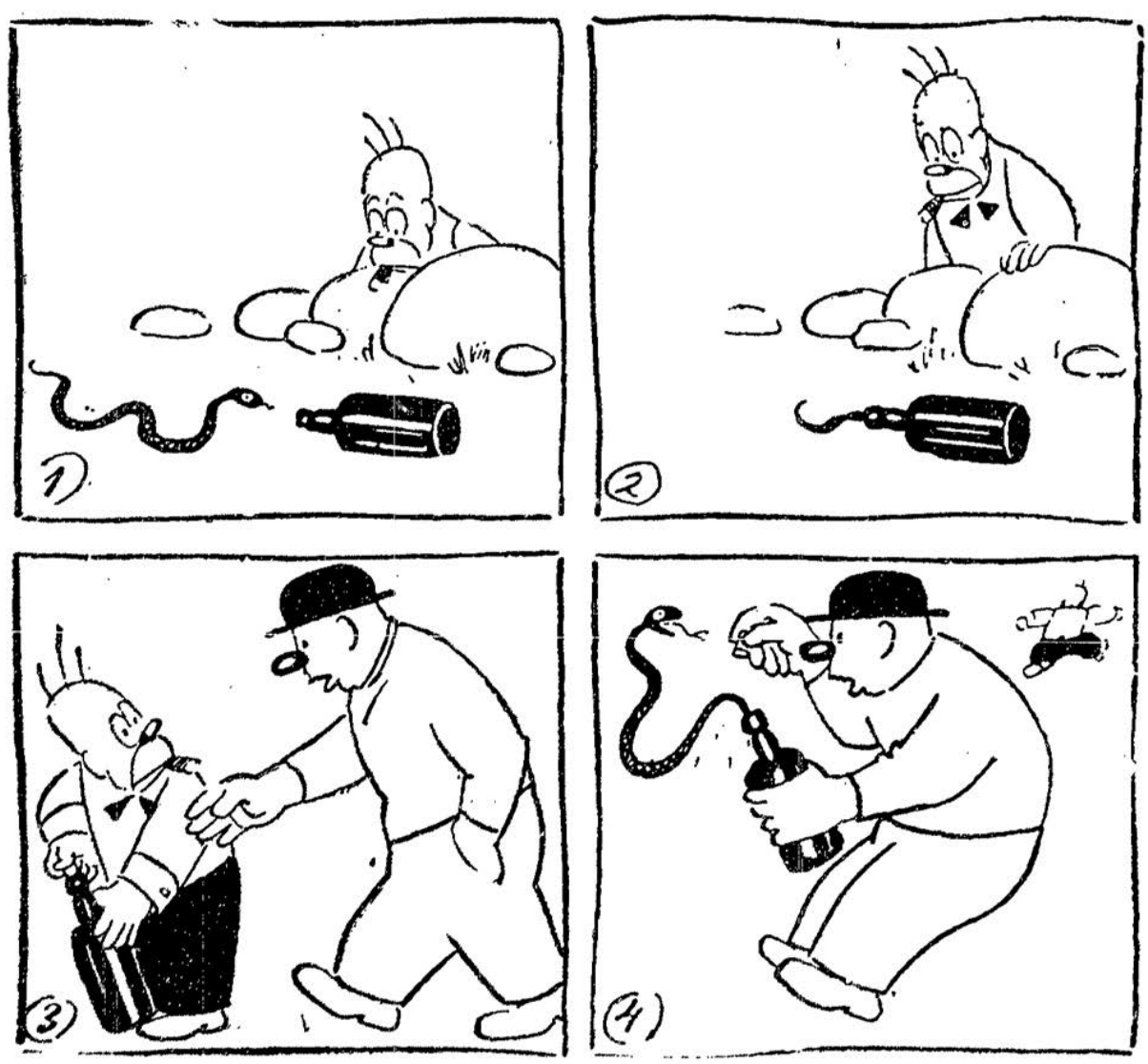

Adamson vangt een slang.

(Sondagsnisse Strix).

Illustratie 1 Jacobsson, Adamson in Nieuw Vlaanderen, 4 september 1937. Vindplaats: Erfgoedbibliotheek Hendrik Conscience Antwerpen

vervolgstrips waarvan dagelijks een korte aflevering verscheen. In de geillustreerde bladen en de kinderbladen domineerden daarentegen de humoristische strips (zie tabel 3 en grafiek 2). De overgrote meerderheid was veeleer in een vervormde, karikaturale stijl getekend. Een meer realistische stijl was in die periode nog vrij beperkt, maar werd toch iets vaker gebruikt naar het einde van het decennium.

Een mogelijke verklaring luidt dat een krant zich door haar dagelijks ritme veel beter tot het publiceren van vervolgverhalen leende dan een tijdschrift waar de lezer minstens een volle week moest wachten op de volgende aflevering. Echter, niet alle beeldverhalen in de Vlaamse kranten waren dagstrips, iets minder dan de helft waren weekstrips (43\%) die slechts één keer per week verschenen. Een gagstrip past per definitie in elk publicatietype. De eerste succesvolle vervolgstrip, Bud Fischer's Mutt and Jeff, vinden we in de Amerikaanse kranten vanaf I907. Tot aan de jaren 


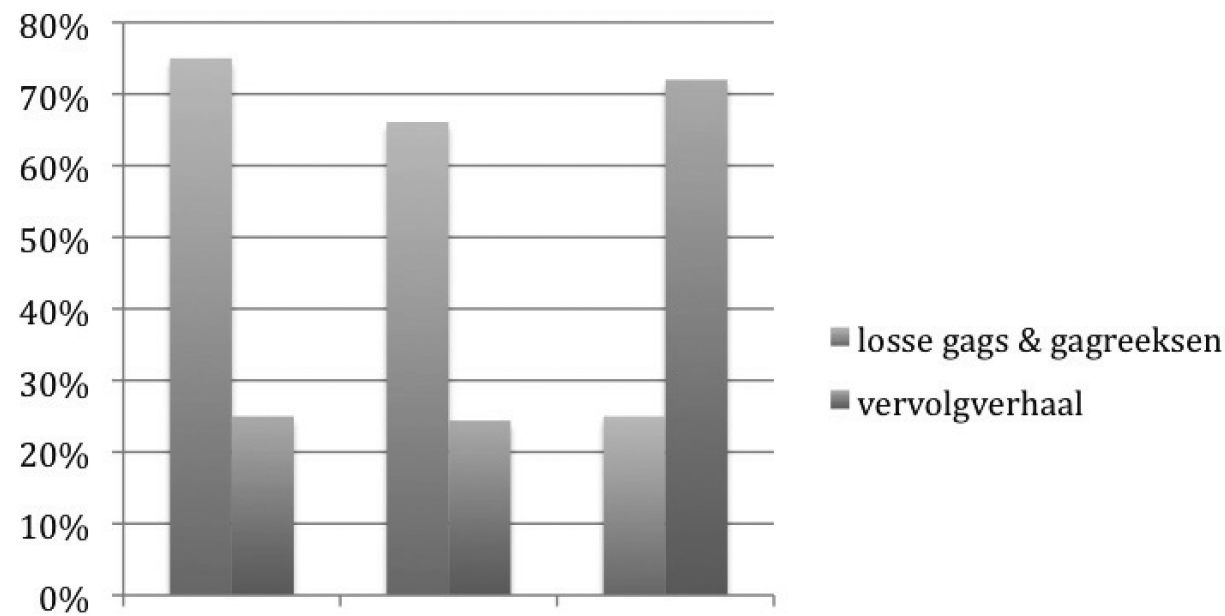

Algemene Kinderbladen Dagbladen tijdschriften

Grafiek 2: Procentuele verhouding tussen humoristische strips en avontuurlijke vervolgverhalen per publicatietype

TABEL 3: $\quad$ Procentuele verhouding tussen humoristische strips en avontuurlijke vervolgverhalen per publicatietype

\begin{tabular}{llll}
\hline & Algemene tijdschriften & Kinderbladen & Dagbladen \\
\hline Losse gags \& gagreeksen & $75 \%$ & $66 \%$ & $25 \%$ \\
Vervolgverhaal & $25 \%$ & $24 \%$ & $72 \%$ \\
\hline
\end{tabular}

dertig domineerden de humoristische vervolgstrips, na de beurscrash van Wall Street werden de meer realistisch getekende avonturenverhalen (Tarzan, Flash Gordon, Terry and the Pirates, Prince Valiant) populair in de Amerikaanse pers en dat sijpelde blijkbaar met enige vertraging ook door naar Europa en meer bepaald Vlaanderen.

\section{Aantal en levensduur beeldverhalen}

Niet alleen de hoeveelheid beeldverhalen die per publicatie verschenen, maar ook de periode waarin een bepaalde stripreeks gepubliceerd werd, geeft een indicatie van hun relatief belang binnen een bepaalde publicatie. Hoe langer een bepaalde stripreeks liep, hoe standvastiger de aanwezigheid van het beeldverhaal in de desbetreffende publicatie was. Aangezien uitgevers rekening hielden met de wensen van hun lezerspubliek, kan een hoge mate van aanwezigheid ook op de populariteit van een 
TABEL 4: $\quad$ Aantal verschillende strips in de tijd per publicatietype

\begin{tabular}{lllll}
\hline & Algemene tijdschriften & Kinderbladen & Dagbladen & totaal \\
\hline I930 & I & 8 & 7 & I6 \\
I93I & 8 & 6 & I & I5 \\
I932 & 3 I & I2 & 6 & 49 \\
I933 & 53 & 20 & 9 & 82 \\
I934 & 28 & 24 & IO & 62 \\
I935 & I8 & 34 & I2 & 64 \\
I936 & 56 & 52 & 24 & I32 \\
I937 & 56 & 2 I & II & 88 \\
I938 & 64 & I9 & IO & 93 \\
I939 & 58 & 22 & 9 & 89 \\
Totaal & 373 & 2 I 8 & IOO & 69 I \\
\hline
\end{tabular}

bepaald beeldverhaal wijzen. Over de manier waarop die Vlaamse publicaties werden samengesteld, waren weinig gegevens beschikbaar. Het staat echter vast dat het grote Amerikaanse syndicate King Features (van Randolph Hearst) een gratis vakblad, Circulation (I916-I933), wereldwijd naar krantenuitgevers stuurde om het eigen aanbod aan strips te promoten. In dat blad werd herhaaldelijk beklemtoond dat de publicatie van strips cruciaal was voor het succes van een krant of tijdschrift.

Om de doorbraak van het beeldverhaal in Vlaanderen kwantitatief te evalueren, was het uiteraard ook van belang om de historische evolutie van de data zorgvuldig te analyseren. Het aantal gevonden strips varieerde immers sterk naargelang het onderzochte jaar: in 1930 kwamen beeldverhalen nog amper voor (in totaal slechts zestien), maar drie jaar later waren ze al veel frequenter ( 82 in totaal) (zie tabel 4 en grafiek 3). Het topjaar was onmiskenbaar I936 met I32 beeldverhalen. Hoewel de productie aan het einde van de jaren dertig opmerkelijk hoger lag dan aan het begin van dat decennium, geeft onze dataset na 1936 toch een vermindering aan. Dit is deels te wijten aan niet teruggevonden publicaties: mochten we ook Bravo (1936-I940) en jaargang I938 van het tijdschrift Robbedoes hebben kunnen opnemen in dit onderzoek, dan zouden de cijfers (in elk geval wat betreft de kinderbladen) hoger geweest zijn. Bij de kranten waren er ook enkele titels die niet tot het einde van de jaren dertig liepen of konden worden onderzocht; dit zou ook onderstaand resultaat kunnen verklaren. De evolutie van de algemene tijdschriften verliep eind jaren dertig zoals verwacht, maar voor de sterke stijging, gevolgd door een flinke duik was er ook niet meteen een verklaring. Hoe dan ook, het volume aan beeldverhalen was in de tweede helft van de jaren dertig ruim verdubbeld: we zien een evolutie van 224 strips in 1930-I934 naar 466 beeldverhalen in de periode I935-I939. 
14 | Tijdschrift voor Mediageschiedenis - I4 [I] 20 II

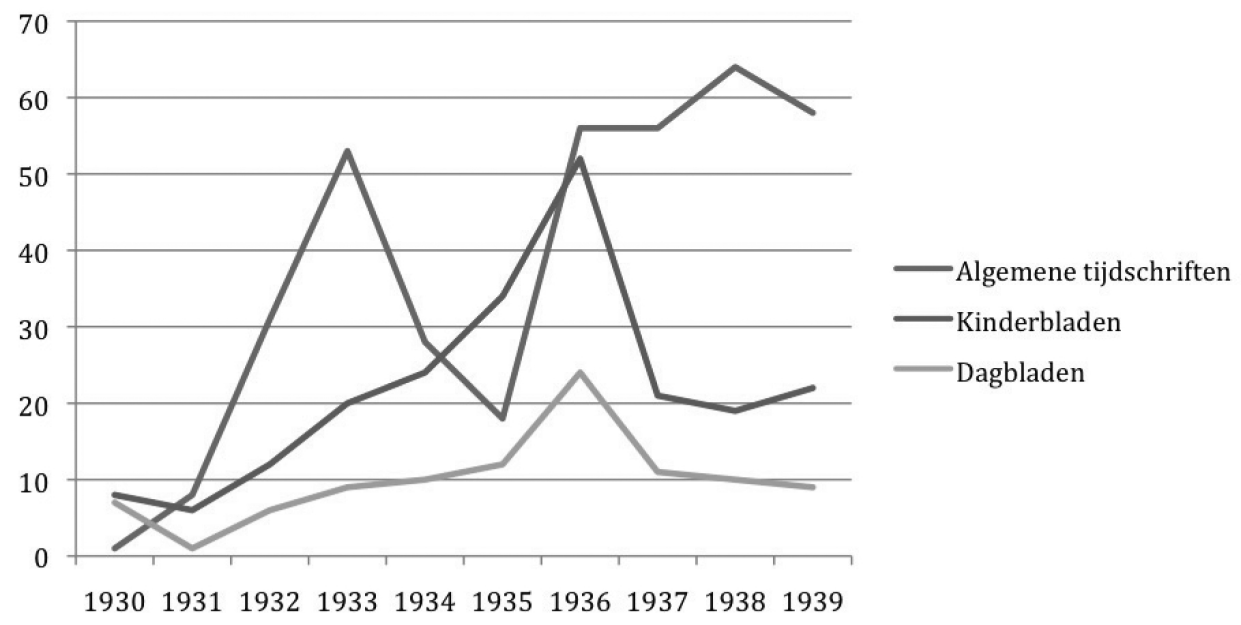

GRAFIEK 3: Evolutie van het aantal strips in de tijd per publicatietype

TABEL 5: $\quad$ Levensduur van een beeldverhaal per publicatietype

\begin{tabular}{llll}
\hline & Algemene tijdschriften & Kinderbladen & Dagbladen \\
\hline Eenmalig & $50 \%$ & $67 \%$ & $\circ \%$ \\
I à 3 maanden & $3 \%$ & $\mathrm{I} 3 \%$ & $24 \%$ \\
4 à 6 maanden & $6 \%$ & $9 \%$ & $46 \%$ \\
7 à I2 maanden & $5 \%$ & $\mathrm{II} \%$ & $\mathrm{I} 4 \%$ \\
Langer dan een jaar & $36 \%$ & $\mathrm{II} \%$ & $7 \%$ \\
\hline
\end{tabular}

Hoe lang een bepaald beeldverhaal in een bepaalde publicatie bleef verschijnen, was sterk verschillend naargelang het publicatietype (zie tabel 5). Terwijl in de kinderbladen en de algemene tijdschriften de meeste strips (respectievelijk 67\% en 50\%) slechts eenmalig verschenen, was de gemiddelde levensduur van een beeldverhaal in een krant ongeveer zeven maanden. Bij de algemene tijdschriften werden langlopende reeksen (van meer dan een jaar) ruim vertegenwoordigd (36\%). Negen beeldverhalen liepen in de krant zelfs langer dan één jaar en bij de kinderbladen waren er zelfs vier die minstens $6_{4}$ maanden liepen (o.a. Fred en Minet van Daan Hoeksema).

\section{Uitzicht van de gepubliceerde beeldverhalen}

Dat het beeldverhaal in Vlaanderen in de jaren dertig op een aantal aspecten sterk afweek van de hedendaagse situatie blijkt al uit het feit dat de overgrote meerder- 


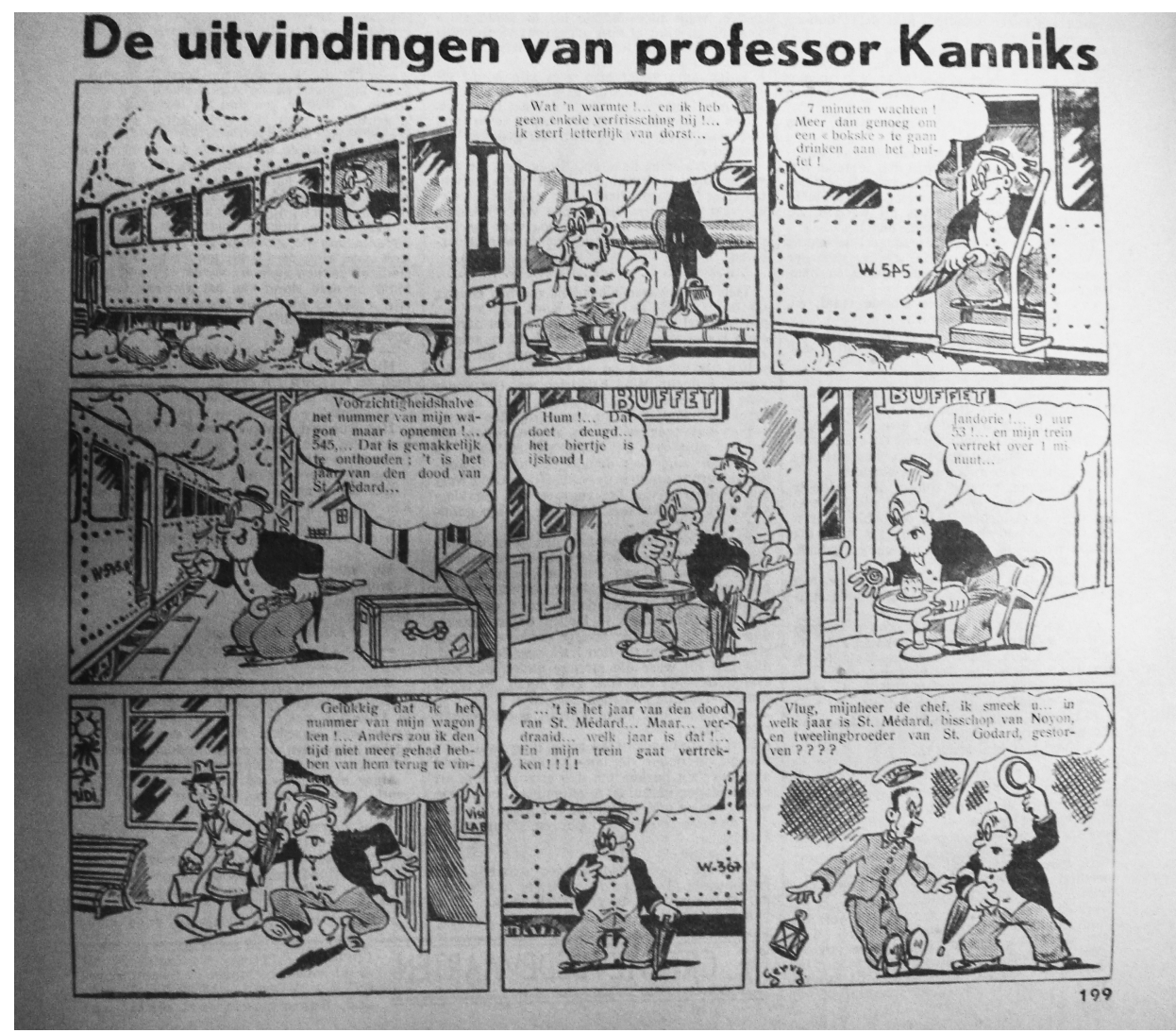

Illustratie 2 Gervy, De uitvindingen van professor Kanniks in Averbodes Weekblad, 26 maart 1939 (originele Franse reekstitel is Les inventions du professeur Pouic). Vindplaats: Centrale Bibliotheek Leuven

heid van de beeldverhalen toen alleen in zwart-wit verscheen. In de kranten waren alle beeldverhalen in zwart-wit, maar in de geillustreerde tijdschriften werd toch één strip op tien in kleur gedrukt. In de kinderbladen ging het zelfs om één strip op vijf. Om binnen het zwart-wit enige grijsnuance te brengen, werden behalve arceringen soms ook rasters gebruikt. We troffen deze techniek aan in $19 \%$ van de beeldverhalen gepubliceerd in de kinderbladen. Voor de geïllustreerde bladen en de kranten ging het respectievelijk om $40 \%$ en $7 \%$. Ons onderzoek geeft eveneens aan dat elk publicatietype, wat de omvang van een afzonderlijke aflevering betreft, blijkbaar de voorkeur gaf aan een bepaald type van strip: zo bestond 70\% van alle beeldverhalen in de kranten uit slechts één strook, bij de geillustreerde tijdschriften was dat 30\% en bij de kinderbladen bijna $8 \%$. Bij de tijdschriften was de meest voorkomende vorm dan weer de driestroken-indeling per strip (zie illustratie 2). Na de Tweede Wereldoorlog zou echter de vierstroken-indeling (o.a. bij Suske en Wiske en Tintin) de standaardindeling worden. ${ }^{\text {T7 }}$ 


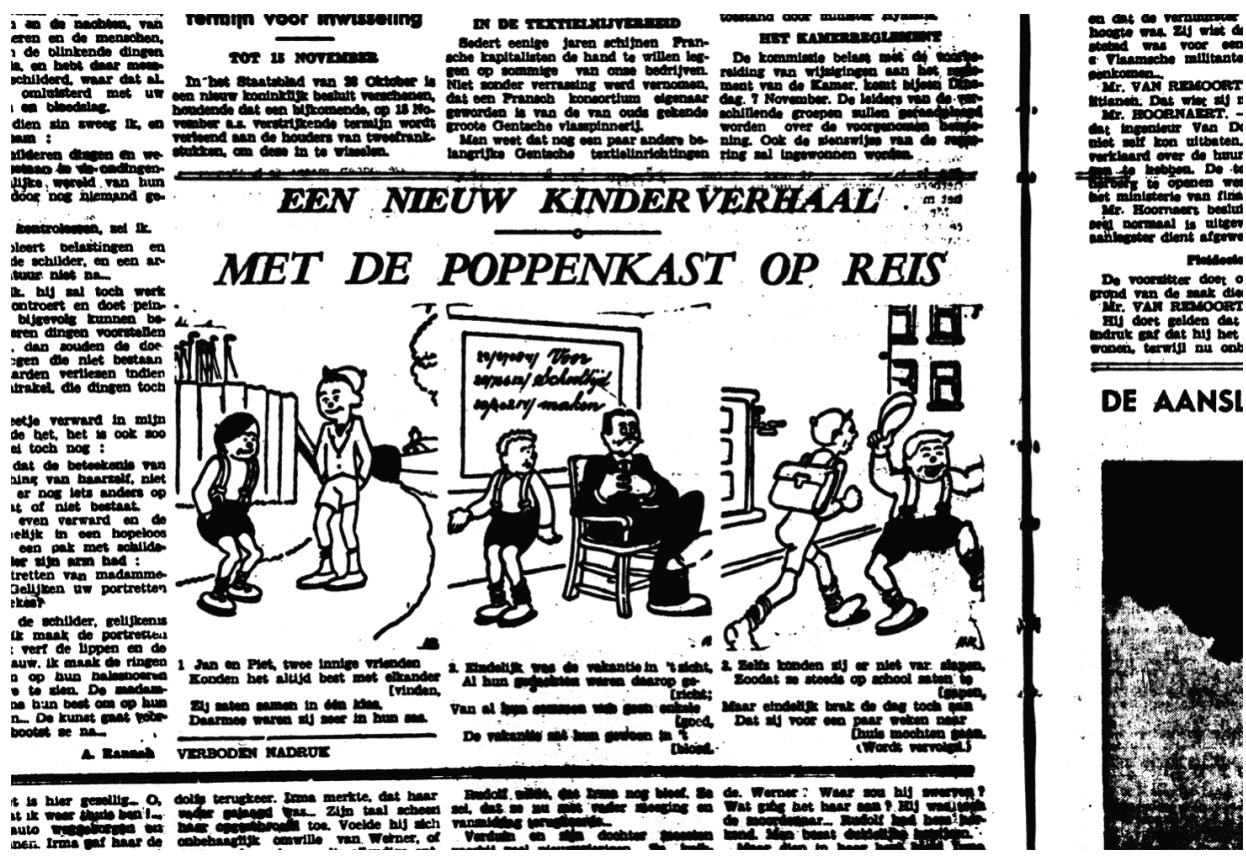

I llustratie 3 Kannegieter, Met de poppenkast op reis in Het Laatste Nieuws, 29 oktober 1933. Vindplaats: Erfgoedbibliotheek Hendrik Conscience in Antwerpen

TABEL 6: $\quad$ Procentuele verhouding tussen het aantal stroken voor een beeldverhaal per publicatietype

\begin{tabular}{llll}
\hline & Algemene tijdschriften & Kinderbladen & Dagbladen \\
\hline I strook & $30 \%$ & I7\% & $70 \%$ \\
2 stroken & I7\% & $22 \%$ & I3\% \\
3 stroken & $34 \%$ & $39 \%$ & $9 \%$ \\
4 stroken & I7\% & I9,7\% & $8 \%$ \\
5 stroken & I\% & I\% & $0 \%$ \\
6 stroken & I\% & I\% & $0 \%$ \\
\hline
\end{tabular}

Kijken we naar het aantal plaatjes per strook (zie tabel 7), dan valt opnieuw het verschil tussen de dagbladen en tijdschriften op. In de dagbladen domineerde duidelijk het systeem van één strook met drie plaatjes (zie illustratie 3). Bij de tijdschriften was er veel meer variatie, maar ook daar werden gemiddeld drie plaatjes per strook gebruikt. Vijf of meer plaatjes per strook waren zeer zeldzaam. We zien hier dus over de verschillende publicatietypes heen toch een zekere systematiek tot stand komen. 
TABEL 7: Aantal plaatjes per strook per publicatietype

\begin{tabular}{llll}
\hline Aantal plaatjes per strook & Algemene tijdschriften & Kinderbladen & Dagbladen \\
\hline I & $20 \%$ & $8 \%$ & $3 \%$ \\
2 & $22 \%$ & $34 \%$ & $\mathrm{I} \%$ \\
3 & $38 \%$ & $46 \%$ & $62 \%$ \\
4 & $\mathrm{I} \% \%$ & $9 \%$ & $\mathrm{I} 6 \%$ \\
5 & $\mathrm{I} \%$ & $2 \%$ & $4 \%$ \\
6 & $\mathrm{I} \%$ & $\mathrm{I} \%$ & $6 \%$ \\
7 & $0 \%$ & $\mathrm{I} \%$ & $0 \%$ \\
\hline
\end{tabular}

TABEL 8: $\quad$ Procentuele verhouding tussen de leesrichtingen per publicatietype

\begin{tabular}{llll}
\hline & Algemene tijdschriften & Kinderbladen & Dagbladen \\
\hline Horizontaal & $83 \%$ & $93 \%$ & $93 \%$ \\
Verticaal & $\mathrm{I} \%$ & $7 \%$ & $4 \%$ \\
Variabel & $\circ \%$ & $0 \%$ & $3 \%$ \\
\hline
\end{tabular}

Niet alleen de plaatindeling was in de jaren dertig nog vrij stroef, ook waren er weinig wisselingen van blikveld van het ene plaatje naar het andere in de kranten en in de kinderbladen. Een veeleer statische beeldkeuze was dominant: $80 \%$ bij de dagbladen en $84 \%$ bij de kinderbladen. Opmerkelijk genoeg was de beeldkeuze in de beeldverhalen die in de algemene geïllustreerde tijdschriften werden gepubliceerd, wel veel dynamischer (66\%). We zien hier dus een opvallende correlatie met het beoogde doelpubliek: hoe meer een beeldverhaal op kinderen gericht was (wat het geval was in dagbladen en kinderbladen), hoe minder dynamisch het verhaal qua blikvariaties in beeld werd gebracht.

Toen het beeldverhaal als ontspanningsmedium in de negentiende eeuw zijn intrede deed, waren er qua lay-out minder strikte conventies dan vandaag. Een strippagina die acht plaatjes ( 2 kolommen van 4 plaatjes) bevatte, kon ofwel in een horizontaal leesparcours (van links naar rechts, rij na rij), ofwel in een verticaal leesparcours (van boven naar onder, kolom na kolom) georganiseerd worden. ${ }^{\text {I } 8}$ In de twintigste eeuw werd de horizontale leesrichting dominant(er) en werd een verticaal leesparcours in de Verenigde Staten of Europa alleen nog gebruikt voor een enkele kolom en niet voor twee of meerdere kolommen naast elkaar. De beeldverhalen die in de Vlaamse pers in de jaren dertig werden gepubliceerd, tonen dit ook aan: de meest voorkomende schikking van de plaatjes was bij alle publicatietypes de horizontale strookindeling, de verticale kolom kwam veel minder voor (zie tabel 8). 
TABEL 9: $\quad$ Procentuele verhouding tussen de verschillende manieren waarop tekst al dan niet werd gebruikt in drie publicatietypes

\begin{tabular}{llll}
\hline & Algemene tijdschriften & Kinderbladen & Dagbladen \\
\hline Tekst onder beeld & $26 \%$ & $60 \%$ & $76 \%$ \\
Tekstballon & $25 \%$ & $\mathrm{I} \%$ & $20 \%$ \\
Woordloos & $38 \%$ & $22 \%$ & $3 \%$ \\
Tekstballon en tekst onder beeld & I2\% & $0 \%$ & $\mathrm{I} \%$ \\
\hline
\end{tabular}

Ten slotte waren er verschillende manieren om een pagina met plaatjes in te delen: er waren strippagina's waarop alle plaatjes dezelfde vorm en grootte hadden, maar er waren ook meer vrije plaatindelingen waarbij plaatjes verschillende groottes of vormen hadden. In het onderzochte corpus waren de eenvormige plaatindelingen nog altijd dominant en waren vrije plaatindelingen nog schaars. We troffen de vrije plaatindeling slechts voor $8 \%$ aan in tijdschriften en voor $29 \%$ in dagbladen. Het overgrote deel van de beeldverhalen zat in de jaren dertig dus nog in een vast stramien, dat een uitloper was van de negentiende-eeuwse roosters van de kinderprenten. ${ }^{19}$

\section{Verschijningsvormen van tekst}

Het negentiende-eeuwse model met tekst onder plaatjes was in de Vlaamse pers blijkbaar nog sterk aanwezig in de jaren dertig (zie tabel 9 en grafiek 4). Zowel in de kranten $(76 \%)$ als in de kinderbladen $(60 \%)$ werden hoofdzakelijk beeldverhalen met tekst onder de plaatjes gepubliceerd (zie illustratie 3). Het betrof dan hoofdzakelijk een in blokjes onderverdeelde tekst: onder elke plaatje stond een afzonderlijk tekstblokje. Dat de tekst doorliep en dus als één blok onder een reeks plaatjes stond, was veel minder courant. Bij de geillustreerde tijdschriften voor volwassenen waren de verschillende categorieën meer in evenwicht, met als grootste groep (38\%) de tekstloze strips (zie illustratie I). Zulke 'stille' strips kwamen iets minder voor in kinderbladen (slechts $22 \%$ ) en waren al helemaal zeldzaam in de kranten (soms kregen ze daar een toegevoegde ondertekst). Spreekballonnen, die tegenwoordig kenmerkend voor de strip zijn, waren in de jaren dertig in de Vlaamse pers dus nog maar beperkt aanwezig en haalden nooit meer dan één strip op vier (in de geïllustreerde bladen). Wel kan men in diverse publicatietypes een relatieve stijging merken van tekstballonnen in de tweede helft van het decennium. Deze evolutie zou na de Tweede Wereldoorlog nog versterkt worden (zie illustratie 2). Bij de kinderbladen kwam die stijging er vooral door de komst van nieuwe titels als Robbedoes; in de oudere kinderbladen valt op dit vlak geen evolutie te bekennen. Het verzet tegen de tekstballon ging soms zelfs zo ver dat een originele Amerikaanse ballonstrip als Mickey Mouse voor publicatie in De Standaard verminkt werd (zie illustratie 4). De 


\section{Dit zijn de avonturen van Mikkie en Bleskop}

Mikkie en zijn neef Bleskop werden in een onbewoond kasteel gelokt, door inge nieurs, die willen proeven nemen met hun schrikkelijke uitvinding : de straal dif hypnotiseert. Voor die proeven, hebben ze Mikkie en Bleskop uitgekozen. De in genieurs hebben zich reeds meester ge maakt van Bieskop. Intusschen zitte
Mipsie, de verloofde van Mikkie en Arabel la, de vrouw van Bleskop angstig te wachten, en worden wanhopig, daar ze zonder eenig nieuws zijn van Mikkie en Bleskol

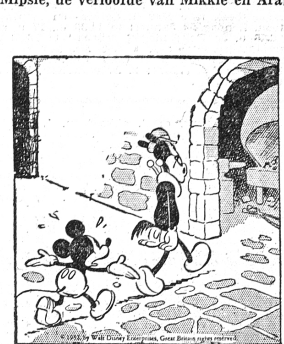

1.) "Vooruit, Bleskop; het wordt tijd dat we naar huis gaan; ik in die gang rond te loopen; weet gij den weg naar buiten? $\gg$ " Neen Mikkie, ik niet; we moeten maar
zoeken tot we den uitgang vinden. Ga maar mee, we zullen deze poort doorgaan, daar zijn we nog niet

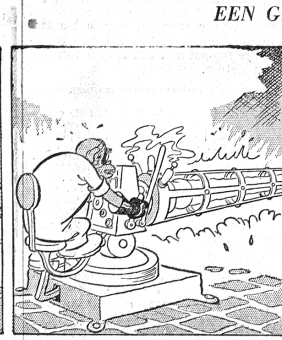

2.) \&Zeg Microbius, kijk gij een even waar Mijnheer Bleskop is, dan
zal tk het toestel in orde brengen "Ik zie Mijnheer Bleskop met zij. vriend Mikkie door de poort naa de smederij gaan $\$$ : zei professor
Microbius. «Goed zoo Microbius, Microbius. "Goed zoo Microbius
verbindt gij nu ons toestel da verbindt gij nu ons toestel dan
kunnen we beginnen : klaar?

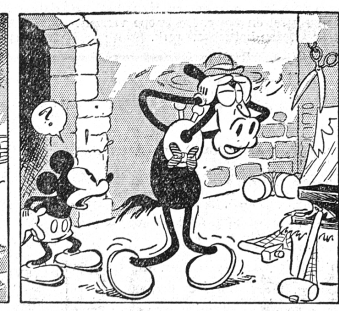

3.) Wat ziet ge er bleek uit, Bleskop : zijt ge niet goed? \& \& $\mathrm{Ik}$ weet niet wat ik heb maar ik voel me zoo duizelig
o.. O... Mikkie, wat is dat nu, alles draait om me heen! En mijn neus begint zoo te jeuken; het is niet uit te houden! \&Ja, dat komt natuuriljk van die neusonders niet, meende Mikn

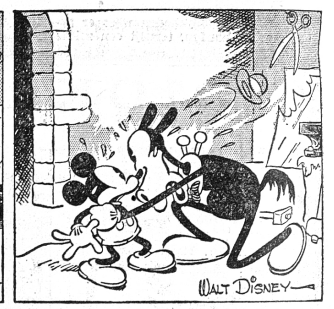

4.) Opeens viel Bleskop voor Mikkie op den grond en riep : " oei, oei, nu krijg il als vuur en het is alsof hij ineen krimpt Wat moet ik doen Mikkie, kunt ge me niet helpen? \& Neen Bleskop, ik kan niets aan doen maar als we thuis kom
zal ik den dokter gaan halen! $\$$

Illustratie 4 Floyd Gottfredson, Mikkie en Bleskop, in De Standaard, 1 februari 1933.

Vindplaats: Centrale Bibliotheek van de K.U. Leuven. De tekstballonnen werden verwijderd en vervangen door tekst onder het beeld

Tekstballon en tekst onder beeld

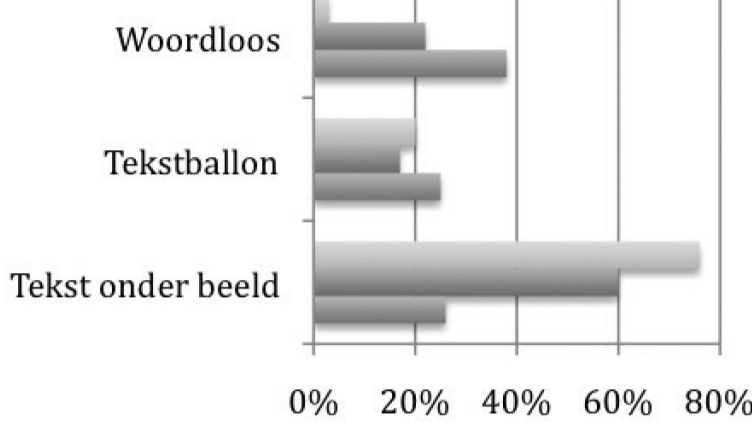

Dagbladen

Kinderbladen

Algemene tijdschriften

GRAFIEK 4: De verschillende manieren waarop tekst al dan niet werd gebruikt in drie publicatietypes

plaatsen waar de tekstballonnen stonden, werden vervangen door een witte vlek in de tekening en de tekst uit de tekstballonnen werd herschreven als ondertekst bij de plaatjes. 
TABEL 10: Aanwezigheid van onomatopeeën per publicatietype

\begin{tabular}{llll}
\hline Onomatopeeën & Algemene tijdschriften & Kinderbladen & Dagbladen \\
\hline Neen & $89 \%$ & $89 \%$ & $82 \%$ \\
Ja & II\% & Iг\% & I $8 \%$ \\
\hline
\end{tabular}

TABEL 11: Aanwezigheid van pictorial runes per publicatietype

\begin{tabular}{llll}
\hline Pictorial runes & Algemene tijdschriften & Kinderbladen & Dagbladen \\
\hline Neen & $24 \%$ & $43 \%$ & $20 \%$ \\
Ja & $76 \%$ & $57 \%$ & $80 \%$ \\
\hline
\end{tabular}

Onomatopeeën of klanknabootsingen die in de tekening zelf staan ('Vrooaar' om het geluid van een snelrijdende wagen te illustreren) vormen tegenwoordig een veelvoorkomend element van het klassieke beeldverhaal. In de jaren dertig waren ze nog vrij zeldzaam (zie tabel Io). Dit mag weinig verwondering wekken daar ook tekstballonnen amper voorkwamen. Er was in het algemeen dus duidelijk een weerstand tegen tekst in beeld, zij het in tekstballonnen, zij het als onomatopeeën. ${ }^{20}$

'Pictorial runes' (zoals bewegingslijnen bij zich snel voortbewegende figuren of voertuigen) waren daarentegen wel een vaak voorkomende techniek en ze kwamen iets meer voor bij karikaturale humoristische strips dan bij realistische vervolgverhalen (zie tabel II).

\section{Besluit}

Dit artikel presenteerde de resultaten van een systematisch kwantitatief onderzoek naar beeldverhalen gepubliceerd in de jaren dertig van de twintigste eeuw, in drie Vlaamse publicatievormen: dagbladen, periodieke publicaties voor volwassenen- en kinderbladen. Een dergelijk vergelijkend onderzoek is vooralsnog zeldzaam in het striphistorisch onderzoek. ${ }^{2 \mathrm{I}}$ Het zou natuurlijk interessant zijn om een gelijksoortig onderzoek voor andere decennia of voor andere landen op te zetten, zodat de ontwikkelingen vergeleken kunnen worden.

Uit het onderzoek blijkt duidelijk dat het stripaanbod in Vlaanderen in de jaren dertig sterk verschilde van het huidige. Zo verschenen de meeste strips toen in zwart-wit, waren tekstballonnen nog geen dominant kenmerk, was er een groter aanbod van kinderbladen met beeldverhalen en waren er nog geen uitermate populaire strips van eigen makelij, zoals tegenwoordig Suske en Wiske, Jommeke of De 


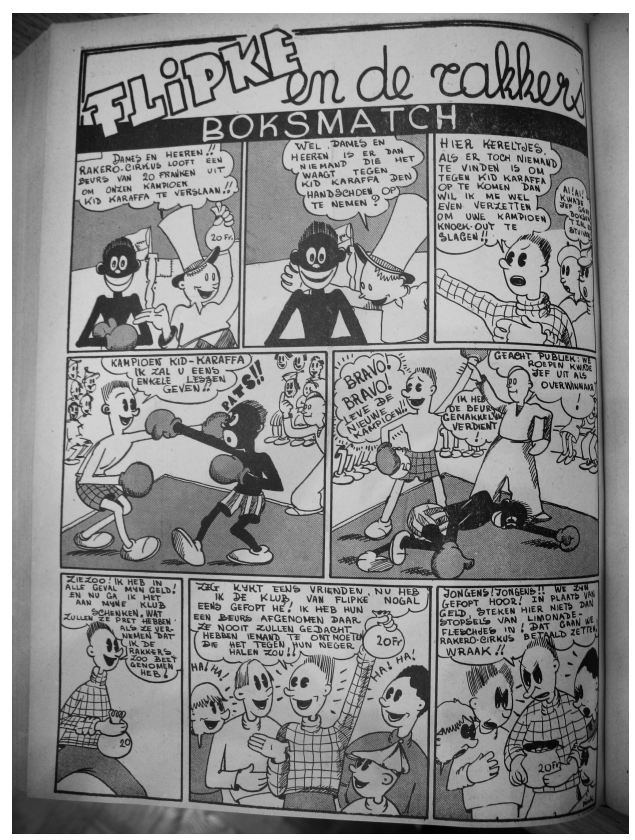

Illustratie 5 Pink, Muziek in de Jungle, in Ons Volkske, 14 januari 1934. Vindplaats: Stadsbibliotheek Antwerpen (EHC)

Kiekeboes. Tegenwoordig worden strips vooral als albums op de markt gebracht, toen was dat nog zeldzaam. Toch waren de jaren dertig vrij belangrijk, omdat het precies in dit decennium was dat het beeldverhaal een vaste voet kreeg in de Vlaamse pers. Het was eveneens in de jaren dertig dat het gebruik van de tekstballon doorbrak. Ons systematisch onderzoek toont aan dat men daarom van een scharnierperiode voor de ontwikkeling van het beeldverhaal in Vlaanderen kan spreken. Verder werd duidelijk dat er, afhankelijk van het publicatietype dat onderzocht werd, niet alleen gelijkenissen maar ook belangrijke verschillen voorkwamen. Elke publicatievorm bleek immers bij voorkeur een bepaald soort beeldverhaal te publiceren. Zo kwamen vervolgverhalen vooral voor in kranten, verschenen woordloze gags vooral in tijdschriften, deden kranten en algemene tijdschriften meer beroep op buitenlandse strips (dagbladen publiceerden vooral beeldverhalen uit Nederland, algemene tijdschriften gaven veeleer de voorkeur aan Scandinavisch werk) en lieten kinderbladen hoofdzakelijk Belgische auteurs aan bod komen. Kortom, het panorama van het beeldverhaal in de Vlaamse pers van de jaren dertig was tamelijk divers en de ontwikkelingen die in dit decennium op gang kwamen, zouden zich zonder het uitbreken van de oorlog allicht nog sneller hebben doorgezet. Pas in de jaren na de bevrijding zouden we de eerste grote populaire naoorlogse stripreeksen van Vlaamse auteurs (Suske en Wiske, Nero, Piet Pienter en Bert Bibber) in de dagbladen zien opduiken. De beeldverhalen zelf die in de Vlaamse pers van de jaren dertig versche- 
nen, mogen nu al vergeten zijn, dit onderzoek wijst erop dat zij de noodzakelijke basis legden voor de definitieve doorbraak van dit populaire medium in Vlaanderen.

\section{Noten}

I De strip in het Vlaanderen van de jaren dertig komt alleen aan bod in de publicaties van de Antwerpse stripverzamelaar Danny De Laet: D. De Laet, Het beeldverhaal in Vlaanderen. Breda, Brabantia Nostra, I977; D. De Laet \& Y Varende, De zevende kunst voorbij. Geschiedenis van het beeldverhaal in België. Brussel, Ministerie van Buitenlandse Zaken en Ontwikkelingssamenwerking, I979.

2 B. Blackbeard \& M. Williams, The Smithsonian collection of newspaper comics. Washington-New York, Smithsonian Institution Press-Harry N. Abrams, I986; B. Blackbeard \& D. Crain (eds.), The Comic Strip Century. Celebrating 100 Years of an American Art Form. Northampton, Kitchen Sink Press, I995; B. Walker, The Comics before 1945. New York, Harry N. Abrams, 2004; Th. Groensteen, La bande dessinée, son histoire et ses maîtres. Paris/Angoulême, Skira Flammarion/le musée de la bande dessinée, 2009; J.J. Gabut, L'Age d'or de la BD. Les journaux illustrés 1934-1944. Paris, Catleya, 200I; L. Grove. Text/Image Mosaics in French Culture. Emblems and Comic Strips. Aldershot, Ashgate, 2005; P. Gravett \& P. Stanburgy, Great British Comics. London, Aurum, 2006; R. Sabin, Comics, Comix a Graphic Novels. London, Phaidon, I996, Il fumetto italiano, go anni avventure disegnate. Storia, autori e personaggi dal Corriere dei Piccoli a Dylan Dog, Milano, Superart, I998.

3 Inzake de verspreiding van Amerikaanse strips in Japan en Latijns-Amerika, zie onder andere: F.L. Schodt, Manga! Manga! The world of Japanese comics. Tokyo, Kodansha, 1997 (I983); J.M. Aurrecoechea \& A. Bartra, Puros Cuentos, La historia de la historieta en México 1874-1934. México D.F., Direccion general de Publicaciones, Direccion General de Culturas Populares, Museo Nacional de Culturas Populares, Grijalbo, I988; C. E. Diaz Castro, 200I. 'La historieta en Chile,' in Revista latinoamericana de estudios sobre la historieta, vanaf vol. 2, nr. 6 tot vol. 4, nr. 15 .

4 P. Lefevre, 'The Battle over the Balloon, The conflictual institutionalization of the speech balloon in various countries', in Image (Q) Narrative, Online Magazine of the Visual Narrative, nr. I4, May 2006.

5 Dit kwam enkel summier aan bod in De Laet, Het beeldverhaal in Vlaanderen.

6 Zowel in theorie als in de praktijk wordt haast altijd een onderscheid gemaakt tussen cartoon en strip. De overgrote meerderheid van wat men als cartoons aanduidt, bestaat uit één plaatje, maar bijvoorbeeld eind negentiende eeuw werden er soms twee plaatjes gebruikt: het eerste plaatje toont een bepaalde actie of toestand en in het tweede volgt dan een reactie of commentaar. Dergelijke uiterst korte sequensen van twee plaatjes worden doorgaans echter niet als een prototypische strip aanzien. Vanaf drie plaatjes krijgt men immers een andere opbouw in de visuele narratie.

7 Het onderscheid tussen de drie publicatietypes was soms niet zo duidelijk, want een krant kon bijvoorbeeld ook wekelijks een apart bijvoegsel of katern drukken dat gericht was op kinderen (bijv. Wonderland bij De Dag). Iets dat binnen de context van een krant verscheen, hebben we consequent in de categorie krant ondergebracht.

8 P. Lefevre, "The Importance of Being "Published". A Comparative Study of Different Comics Formats', in A. Magnussen \& H-C. Christiansen, Comics \& Culture, Copenhagen, Museum Tusculanum at the University of Copenhagen, 2000, p. 9I-I05.

9 Aan de hand van de online databank van het Abraham-archief en met behulp van het naslagwerk van E. De Bens \& K. Raeymaeckers, De Pers in België; het verhaal van de Belgische dagbladpers gisteren, vandaag en morgen, (Leuven, LannooCampus, 2007) hebben we een selectieve lijst opgesteld van achttien Vlaamse dagbladen die verschenen tussen I930 en I939. In zes kranten werden geen beeldverhalen gevonden, maar wel in de overige twaalf dagbladen, die we hier rangschikken volgens de mate waarin ze beeldverhalen opnamen (tussen haakjes worden de onderzochte jaren vermeld, omdat niet van elk dagblad de tien volledige jaren beschikbaar waren):

I) De Dag (i934 tot en met I939)

2) Het Laatste Nieuws (I930 tot en met I939)

3) De Nieuwe gazet (1932 tot en met 1939) 
4) De Volksgazet (I930 tot en met I933; I936 tot en met I939)

5) De Schelde (I934 tot en met I936)

6) Het Handelsblad van Antwerpen (I932 tot en met I937)

7) Het Belang van Limburg (I934, 1937)

8) Volk en staat (1936, I937)

9) Het Nieuwsblad (I930, I933 tot en met I939)

Iо) De Standaard (I932 tot en met I939)

II) Het Nieuws van den dag (I939)

I2) De Antwerpsche courant (I938 tot en met I939)

Io Om een lijst van mogelijke geïllustreerde tijdschriften voor volwassenen samen te stellen, deden we beroep op bibliografische werken met betrekking tot literaire tijdschriften van voor I940, geschiedkundige boeken over de pers in België en overzichtlijsten uit de bibliotheekcollecties van de centrale bibliotheek Leuven, Erfgoedbibliotheek Antwerpen en de Koninklijke bibliotheek Brussel: R. Roemans, R. \& H. Van Assche, De tijdschriften opgericht voor 1940. Antwerpen, Roemans-stichting, I970; L. Sips, Vlaamse Literaire Tijdschriften (1850-1960). Antwerpen: Centrum voor Studie en Documentatie, I979; E. De Bens $\&$ K. Raeymaeckers, De Pers in België; C. Sorgeloos \& L. Struye, 150 jaar pers in kijken, Brussel, Gemeentekrediet van België, I980. De onderzochte tijdschriften waren Humoradio, $A B C$, De Snuiver, De Zondagsvriend, Pinnekensdraad, Gewas/Rugo, Lichte Kost, Opgang, Jong Dietschland, Sirene, Teekenen des Tijds, Nieuwe Tijd, Nieuw Vlaanderen, Hooger Leven, Revue Verbroken Boeien, Omroep / Omroeperke, Averbode's Weekblad, Het Vlaamsche Volk / Het Vlaamsche Land, Koekoek en Radiopost. De twee titels die niet konden worden geraadpleegd waren het socialistisch tijdschrift Voor allen (niet meer beschikbaar ter inzage in de Koninklijke bibliotheek Brussel) en De Haardvriend (niet meer beschikbaar in de Erfgoedbibliotheek Antwerpen).

II Om een zo volledig mogelijk corpus af te bakenen van de Vlaamse kinderbladen die verschenen in de periode van I930 tot en met I939 baseerden we ons op Marjoke Rietveld-van Wingerden's Jeugdtijdschriften in Nederland en Vlaanderen 1757-1942. (Leiden, Primavera Pers, I995). Na het wegfilteren van alle jeugdbladen uit Nederland bleef een lijst van 28 Vlaamse kinderbladen over voor de onderzochte periode. In de volgende I4 titels werd minstens één beeldverhaal aangetroffen: Annalen van het Pauselijk Genootschap der Heilige Kindsheid, De Kindervriend, Het kinderland, Jeugd, Jeugdland, Na de school, Ons Kinderland, Ons volkske, Pro Juventute, Robbedoes, Rood-Kruis der Jeugd, Voor en door onze kinderen, Wonderland en Zonneland. Geen strips aangetroffen in de onderzochte exemplaren van De Klaroen (I933-I940), De Kleine Vlaming (I9I4-I940), Het Communieklokje (I907-I939), Jeugd en Wereldvrede (I928-I940), Jongensleven (I93I), Kindergeluk (I924-I938), Lenteweelde (I925-I93I), Missieklokje voor Kinderen (I925-I94I), Nooit meer (1932-I935), Onze Jeugd (I920-I933), Tribuun der Kinderen (I928-1940), Uit onze Pen (I93I-I934). Alleen de kinderbladen Bravo (I936-I943) en Jeugdkerkblad Onze Vriend (I930-I934) werden niet teruggevonden in een openbaar toegankelijke collectie en konden niet worden opgenomen in het onderzoek. Van de andere 26 kinderbladen werden exemplaren in vijf bibliotheken en archieven teruggevonden. De meeste kinderbladen konden in de Erfgoedbibliotheek Hendrik Conscience (EHC) oftewel de stadsbibliotheek van Antwerpen geraadpleegd worden. Ook het Katholiek archief- en documentatiecentrum (KADOC) van de Katholieke Universiteit Leuven (KUL) bleek over een ruime collectie aan Vlaamse kinderbladen uit de jaren dertig te beschikken. De centrale bibliotheek van de KUL en het bijhorende Tabularium waren ook van dienst. Het stripblad bij uitstek - Robbedoes - was deels te raadplegen in het Brusselse Stripmuseum. I2 Een volledig verslag van elk publicatietype apart kan men vinden in drie Masterproeven van de Faculteit Sociale Wetenschappen (opleiding Communicatiewetenschappen) van de K.U. Leuven: K. Aerts, Het beeldverhaal in de Vlaamse dagbladpers tijdens de jaren 1930. Inventaris en beschouwing, 2010; T. Caenepeel, Het beeldverhaal in de Vlaamse geillustreerde tijdschriften van de jaren 1930, 2010; D. Minet, Het beeldverhaal in de Vlaamse kinderbladen van de jaren 1930, 2010. Deze Masterproeven werden telkens begeleid door promotor P. Lefevre.

I3 Rietveld-van Wingerden, Jeugdtijdschriften in Nederland en Vlaanderen: 1757-1942, p. 2 I7.

I4 P. Lefevvre, 'Congo Drawn in Belgium. The Representation of Congo, Rwanda and Burundi in French-language Belgian Comics', in M. McKinney (ed.), History and Politics in French-Language Comics, University Press of Mississippi, 2008, p. I66-I85. Typisch marxistisch georiënteerde ideologische studies van strips zijn onder andere: A. Mattelart \& A. Dorfman, Para leer al Pato Donald, Ediciones Universita- 
24 Tijdschrift voor Mediageschiedenis - I4 [I] 20 II

rias de Valparaiso, I97I; J. Malcorps \& R. Tyrions, De papieren droomfabriek, Leuven, Infodok, I984; W. Leguèbe, La société des bulles, Bruxelles, Vie ouvrière, I977.

I5 Lefèvre, 'The Conquest of Space', in European Comic Art, jg. 2, nr. 2, 2009, p.227-252.

I6 P. Sanderhage, PIB Copenhagen 100, PIB Copenhagen, I999.

I7 P. Lefevre, 'The Conquest of Space', p. 252.

I8 Idem, p. 233-235.

I9 Idem, p. 235 .

20 P. Lefevre, 'The Battle over the Balloon'.

2I P. Lefèvre, 'Researching comics on a global scale', in J. Berndt, (ed.) Global Manga Studies, vol. I Kyoto conference proceedings Comics Worlds and the World of Comics: Towards Scholarship on a Global Scale, International Manga Research Center, Kyoto Seika University, 2010, p. 85-95. 